\title{
Problems of nutritional assessment in the community
}

\author{
Jacqueline Edington \\ Abbott Laboratories, Abbott House, Norden Road, Maidenhead, Berkshire SL6 4XE, UK
}

\begin{abstract}
The present paper explores the problems associated with assessment of nutritional status in the community and reviews the literature related to this subject. The first problem is one of terminology, since a logical first step before assessment is screening, which identifies characteristics known to be associated with dietary or nutritional problems. Its purpose is to differentiate individuals who are at high nutritional risk or have poor nutritional status. There are certain factors which should alert the primary health care team to the fact that nutritional intake may be reduced and that risk of malnutrition is increased. These include disease condition, functional disabilities, inadequate or inappropriate food intake, poor dentition or difficulty swallowing, polypharmacy, alcoholism, depression, poor social circumstances or recent discharge from hospital. Patients suffering from these factors need to be identified so that screening becomes a routine part of their medical treatment. At-risk groups include the elderly, the chronically ill, those with cancer and neurological disorders, post-surgical patients and children with developmental disabilities. In the community, practice and community nurses see the majority of at-risk patients and should carry out screening. A number of screening tools have been developed for community use. Most are aimed at the elderly population, but there are others designed to assess nutritional risk in children with developmental disabilities and the general population. These are reviewed and problems of content and validity identified. Some problems associated with nutritional assessment are also reviewed.
\end{abstract}

Nutritional status assessment: Nutritional screening tools: Malnutrition

During the last few years it has become increasingly apparent that malnutrition remains undiagnosed, and therefore frequently untreated, in patients in hospitals. This may be due to lack of knowledge of the clinical consequences, or the notion that nutritional assessment on admission is unimportant. A recent study has shown that up to $40 \%$ of patients are malnourished on admission to hospital (McWhirter \& Pennington, 1994). The important question is: why does this occur? The obvious answer seems to be that as patients' health deteriorates in the community there is a concomitant deterioration in their nutritional status, and this remains unrecognized by the primary health care team.

But why does malnutrition remain unrecognized in the community? The present paper aims to explore the problems associated with assessment of nutritional status in the community, and suggest possible solutions and areas for further research.
Assessment or screening in the community?

The first problem is one of terminology. The title of the present paper refers to problems of assessment in the community, but a logical first step before assessment is screening. Nutritional screening is defined as: "the process of identifying characteristics known to be associated with dietary or nutritional problems. Its purpose is to differentiate individuals who are at high risk of nutritional problems or have poor nutritional status' (Barrocas et al. 1995). Screening is one of the first steps that can be taken to address nutrition-related problems (Dwyer, 1991). Clearly there are groups of patients who, by nature of their disease condition, may be at risk. In a study of the prevalence of malnutrition in the community it was found that $11 \%$ of post-surgical patients (Edington et al. 1997) and up to $10 \%$ of those with cancer and chronic disorders were malnourished (Edington et al. 1996). These patients are 
representative of those who need to be screened to determine who needs full nutritional assessment. It is also these patients who are typical of those found to be malnourished on admission to hospital (McWhirter \& Pennington, 1994).

After screening certain defined populations to identify those at risk, the next logical step is nutritional assessment. This is defined as: "the measurement of indicators of dietary or nutrition-related factors to identify the presence, nature and extent of impaired nutritional status of any type' (Barrocas et al. 1995). Intervention can then occur where appropriate. The issues of who does this assessment and intervention, and how it is done, will be addressed later in the present paper.

\section{Which patients should be screened and assessed in the community?}

The next problem is to determine who needs nutritional screening, assessment and intervention in the community. There are certain factors which should alert the primary health care team to the fact that nutritional intake is likely to be reduced and that there is increased risk of malnutrition. These factors include disease condition, functional disabilities, inadequate or inappropriate food intake, poor dentition or difficulty swallowing, polypharmacy, alcoholism, depression, poor social circumstances or recent discharge from hospital. Patients suffering from any or all these factors need to be identified so that screening becomes a routine part of their medical treatment (White, 1994).

One group of people who should be screened routinely are the elderly, including the frail elderly (Ham, 1994), elderly people in nursing homes (Chernoff, 1994), those attending their general practitioners' clinics (Ham, 1994) and those requiring home care (Lipschitz, 1994). In the USA it has been shown that $74 \%$ of meals-on-wheels recipients were at risk of poor nutritional status (Coulston et al. 1996). Furthermore, McWhirter \& Pennington (1994) have shown that $43 \%$ of elderly patients admitted to hospital from the community were malnourished.

Some other groups of patients who require regular screening and assessment are the chronically ill, and those with cancer and neurological disorders, many of whom are also elderly (Barrocas et al. 1995). Children with developmental disabilities are also at increased nutritional risk (Campbell \& Kelsey, 1994).

\section{Identification of at-risk patients in the community: who should do it and how is it done?}

In the community, practice and community nurses see the majority of at-risk patients, and it is these members of the primary health care team who should, ideally, carry out screening. According to Grindel \& Costello (1996) nurses in ambulatory clinics, home care, doctors' offices and longterm care facilities should conduct routine nutrition screening of their patients. But if screening and assessment are to take place in the community, the members of the primary health care team must be provided with simple tools to accomplish this and training in how to use them. The problem of how patients should be screened is a major one. Currently, there are no national reference standards by which to measure nutritional status, and these are urgently needed if we are to obtain consistency in screening and assessment. Furthermore, any screening tool which is developed for use in the community needs to be appropriate for the situation in which it is to be used, i.e. the tool needs to take into account the fact that the health care personnel carrying out the assessments may not have scales or stadiometers with which to weigh and measure patients, and they may not have access to clinical chemistry results.

Although there are many published papers describing nutritional screening tools which are used in hospitals (Westin et al. 1988; Gianino \& St John, 1993; Hasse et al. 1993; Elmore et al. 1994; Scanlan et al. 1994; Reilly, 1996), there are few which describe tools which have been developed for community use. One has been described by Gilford \& Khun Khun (1996). Eight nutritional risk factors or categories were included in the tool which was piloted in thirty-five patients. Unfortunately, the methods used to develop the tool are not described in detail in the paper, nor is a copy of the tool included, so it is not clear whether the patient has to be weighed and measured. Hickson \& Hill (1997) describe the adaptation for use in the community of a tool originally designed for hospital use (Reilly et al. 1995). This tool requires community nurses to measure BMI (weight/height ${ }^{2}$ ), which could create difficulties if patients are being seen at home and scales and stadiometers are not available, or if the patient is bed bound. As with most of the assessment tools which give weightings to the questions, it is not clear how these were derived. In addition, the tool has been validated for hospital use, but this was carried out using small numbers of patients. However, the adapted tool was validated for use in the community using a larger sample of ninety-five elderly subjects (Mullan et al. 1996).

There have been several tools developed for screening nutritional risk and assessing nutritional status in the elderly. The most widely used was developed by The Nutrition Screening Initiative, a collaboration between The American Academy of Physicians, the American Dietetic Association and the National Council on Ageing (The Nutrition Screening Initiative, 1994). White (1994) comprehensively describes the risk factors for poor nutritional status in the elderly, most of which were included by The Nutrition Screening Initiative (1994). This initiative incorporates screening and assessment at several different levels, the first (Table 1) being a self-administered questionnaire entitled 'Determine your nutritional health'. This is a checklist of ten questions incorporating the ten warning signs of poor nutritional health: disease, eating poorly, tooth loss or pain, economic hardship, reduced social contact, multiple medications, involuntary weight loss or gain, needing assistance in self care, and elderly (above age 80 years). The first letter of each question spells the acronym DETERMINE. Once an elderly person has been found to be at nutritional risk, that person should then be assessed further by a social service or health care professional using the level I screen, or by a physician or other primary health care provider using the level II screen (The Nutrition Screening Initiative, 1994). This tool has been used extensively in the USA (Posner et al. 1993; Coulston et al. 1996; Jensen et al. 1997; Sahyoun et al. 1997) and, although it has not been formally validated, in these studies it has been found to be 
reasonably accurate in assessing nutritional risk in the elderly.

The nutritional risk index is another tool which has been designed for use with older persons (Wolinsky et al. 1986). The focus of the nutritional risk index is to determine the risk of developing nutritionally-related conditions in the elderly, rather than determining actual nutritional status. So instead of identifying causal relationships between specific diseases and nutritional status, the tool aims to screen patients to identify those who would benefit from further diagnostic evaluation, and possibly preventive intervention. The nutritional risk index has sixteen questions which are designed to assess five dimensions of nutritional risk: mechanics of food intake, prescribed dietary restrictions, morbid conditions affecting food intake, discomfort associated with the outcomes of food intake and significant changes in dietary habits (Table 2). This tool has been used extensively in the USA, and a series of studies to establish validity and reliability have been carried out (Wolinsky et al. 1986, 1990).

In Europe, Guigoz et al. (1994, 1996) have developed and validated a mini nutritional assessment to evaluate risk of malnutrition in the elderly. This tool includes four categories of assessment: anthropometric assessment, dietetic assessment, subjective assessment and global evaluation. The global evaluation section includes questions about living independently, prescription drug use, psychological stress and acute disease, mobility, dementia and skin conditions. The scoring system categorizes patients as normal (having adequate nutrition), borderline (at risk of malnutrition) or undernourished. The tool requires some measurement of biological markers, but there is no section

Table 1. Determine Your Nutritional Health; self-administered questionnaire (Adapted from Dwyer, 1991)

\begin{tabular}{|c|c|}
\hline & Yes $^{\star}$ \\
\hline \multicolumn{2}{|l|}{$\begin{array}{l}\text { I have an illness or condition that made me change the kind } \\
\text { and/or amount of food l eat }\end{array}$} \\
\hline I eat fewer than two meals per $d$ & 3 \\
\hline I eat few fruits or vegetables or milk products & 2 \\
\hline \multicolumn{2}{|l|}{ I have three or more drinks of beer, liquor or wine almost } \\
\hline \multicolumn{2}{|l|}{$\begin{array}{l}\text { I have tooth or mouth problems that make it hard for me to } \\
\text { eat }\end{array}$} \\
\hline I don't always have enough money to buy the food I need & 4 \\
\hline I eat alone most of the time & 1 \\
\hline $\begin{array}{l}\text { I take three or more different prescribed or over-the-counter } \\
\text { drugs daily }\end{array}$ & 1 \\
\hline \multicolumn{2}{|l|}{ Without wanting to, i have lost or gained $4.5 \mathrm{~kg}(10 \mathrm{lb})$ in the } \\
\hline \multicolumn{2}{|l|}{$\begin{array}{l}\text { I am not always physically able to shop, cook and/or feed } \\
\text { myself }\end{array}$} \\
\hline Totalt & 21 \\
\hline \multicolumn{2}{|l|}{$\begin{array}{l}\text { Scores for individual questions were assigned arbitrarily. } \\
\text { Score: } 0-2 \text { good, recheck your nutritional score in } 6 \text { months; } 3-5 \text {, you are at } \\
\text { moderate nutritional risk, see what can be done to improve your eating hab- } \\
\text { its and lifestyle. Your office on ageing, senior nutrition programme, senior cit- } \\
\text { izens or health department can help. Recheck your nutritional score in } 3 \\
\text { months; } 6 \text { or more, you are at high nutritional risk, bring this checklist next } \\
\text { time you see your doctor, dietitian or other qualified health or social service } \\
\text { professional. Talk with them about any problems you may have. Ask for help } \\
\text { to improve your nutritional health. }\end{array}$} \\
\hline
\end{tabular}

which includes these markers, and it is unclear when biological markers should be incorporated into the final assessment. In addition, the anthropometric section requires the patient to be weighed and anthropometric measurement to be carried out, so it could not be used practically by community nurses to assess patients at home.

In the UK, dietitians from the Nutrition Advisory Group for Elderly People have produced a nutrition assessment checklist for community care workers to identify the potential nutritional problems of elderly clients (Nutrition Advisory Group for Elderly People, 1992). The list asks general questions about eating habits, weight change, use of supplements (e.g. Complan; Farleys, Kendal, Cumbria, UK; Build-Up; Nestlé, Aylesbury, Bucks., UK) and laxatives, and has four sections aimed at identifying deficiencies of particular nutrients ( $\mathrm{Fe}$, vitamin $\mathrm{C}, \mathrm{Ca}$ and vitamin $\mathrm{D}$, and fibre). Advice is given in each section about how to take appropriate action to improve intake. Reliability and validity of the checklist have not been established.

Children with developmental problems are a vulnerable group whose nutritional status needs to be monitored regularly. Campbell \& Kelsey (1994) in the USA have developed the Parent Eating and Nutrition Assessment for Children with Special Needs (PEACH) survey, which is a checklist of questions designed to be administered by the child's primary caregiver. The self-reporting format was designed to be similar to other screening instruments (Achenbach \& Edelbrock, 1983; Posner et al. 1993). Six developmental paediatricians assessed the questions for content and face validity, then assigned scores to each question. The tool was validated in seventy-nine children by comparing the total score obtained using the PEACH survey

Table 2. Questions appearing in the nutritional risk index (Adapted from Wolinsky et al. 1986)

Question

Do you wear dentures?

In the past month, have you taken any medicines prescribed by a doctor?

Have you ever had an operation on your abdomen?

In the past month, have you taken any medicines that were not prescribed by a doctor?

Do you have any troubles with your bowels that make you constipated or give you diarrhoea?

Are there any kinds of foods that you don't eat because they disagree with you?

Do you have trouble biting or chewing any kind of food?

Do you have an illness or condition that interferes with your eating?

Do you smoke cigarettes regularly now?

Are you on any kind of special diet?

Have you ever been told by your doctor that you were 'anaemic' (had iron-poor blood)?

Have you had any spells of pain or discomfort for $3 \mathrm{~d}$ or more in your abdomen or stomach in the past month?

Do you have an illness that has cut down on your appetite?

Did you have trouble swallowing at least $3 \mathrm{~d}$ in the last

month?

Did you have any vomiting at least $3 \mathrm{~d}$ in the last month?

Have you gained or lost any weight in the last $30 \mathrm{~d}$ ? (note: net gain or loss must have exceeded $4.5 \mathrm{~kg}$ (10 lb) 
with a nutritional assessment by a dietitian. This tool was found to have a sensitivity of $88.6 \%$ and a specificity of $90.9 \%$, with an overall predictive value of $88.6 \%$. The authors conclude that, in children with developmental problems, the PEACH tool provides a quick method of screening out unnecessary referrals and maximizes effective use of the dietitian's time.

One group of dietitians in the UK is currently collaborating to design a tool for use with children and adults with learning disabilities in the community ( $\mathrm{K}$ Jeffereys, personal communication). Another group in the UK (Bryan et al. 1998) has also developed and validated a screening tool for clients with learning difficulties. The screening form has questions about food frequency, weight and nutrition-related problems. This tool requires the client to be weighed and his or her height measured, which could create difficulties for clients in wheelchairs.

Ward et al. (1998) have developed a screening tool for use in general practice in the UK. In its development the investigators constructed a list of questions which required only yes or no answers, which dietitians felt would be predictive of nutritional risk. Community nurses then administered the questions to 507 patients, and within $4 \mathrm{~d}$ a dietitian conducted a full nutritional assessment. Discriminant analysis and multiple regression analysis were then used to determine which questions were predictive of nutritional risk, and to assign weightings to each question. The questions are shown in Table 3. Patients are categorized according to their level of risk. There are three categories of scores (0-6 not at risk, $7-16$ possible or probable risk, $\geq 17$ malnourished), and the tool has a positive predictive value of $94.6 \%$ and a negative predictive value of $81.1 \%$. It is called the screening in practice tool and is intended to alert health care professionals to the fact that nutritional status is an important part of overall health and well-being of the patient.

Green \& McLaren (1998) have comprehensively reviewed a number of nutrition screening and assessment tools which have been developed for use in the community.

Table 3. Screening in practice tool (Adapted from Ward et al. 1998)

\begin{tabular}{lc}
\hline Question & Score $^{\star}$ \\
\hline Do you often have difficulty with eating or chewing food? & 2 \\
At mealtimes, do you often have a drink instead of eating & 4 \\
food? & \\
Do you often feel full very quickly when you first start eating? & 2 \\
Has your appetite decreased over the last few months? & 1 \\
Do you often feel as though you are going to be sick? & 4 \\
Has your clothing recently started to feel loose? & 1 \\
Do you need help with cooking? & 2 \\
Does the patient look thin? & 6 \\
Has the patient had any involuntary weight loss during the & 4 \\
last 3 months? & \\
Total score & 26 \\
\hline
\end{tabular}

* Assigned by multiple regression analysis.

t $0-6$, not at risk; $7-16$, possible or probable risk; $\geq 17$, malnourished.

\section{What to do after screening?}

Once patients have been found to be at nutritional risk, the community dietitian should take responsibility for conducting a full assessment in the community. However, there are no national reference standards by which to measure nutritional status, and these are urgently needed if we are to obtain consistency in nutritional assessment. In addition, the reference standards for anthropometry which are currently being used for those over the age of 65 years are standards from the USA and the UK from the 1980s (Bishop et al. 1981; Frisancho, 1981; Burr \& Phillips, 1984). BMI is a simple, quick and easy measurement which translates across time and nationalities, but cut-off points for categories of nutritional status need to be agreed. In addition, the issue of whether to include both under- and overnutrition in nutritional assessment needs to be addressed, since both can be considered to increase health risk.

Klein et al. (1997) have reviewed nutritional assessment methods, and conclude that there is no gold standard for determining nutritional status because there is no universally accepted definition of malnutrition. Suffice it to say that in the absence of a gold standard, the community dietitian will use his or her clinical expertise to determine each individual patient's nutritional status and the best course of action to be taken. Some problems which dietitians need to consider are: how to assess patients with oedema, fluid overload, heart failure, or dehydration; how to address the issue of elderly patients whose height decreases with age; what to do about patients with neurological disorders leading to malnutrition, since this degeneration will not reverse with nutrition; how to assess bed-bound patients.

Once the dietitian has completed a full assessment and determined that intervention is appropriate, it is then his or her responsibility to follow up regularly on an individual basis to ensure that the treatment remains appropriate.

\section{Recommendations for the future}

1. A definition of malnutrition needs to be established and accepted.

2. National reference standards for anthropometric measurements by which to evaluate body composition need to be established for both the young and elderly populations, since the body size of the population has changed over the last 20 years, and those currently used are outdated.

3. If BMI is to be used as a standard measurement of nutritional status, universally-accepted cut-off points for each BMI category need to be agreed.

4. Nutritional screening needs to be incorporated as a routine part of yearly check-ups for people over 75 years, and for all patients deemed to be at risk because of their disease condition. In addition, all health care professionals should be educated about the contribution of nutritional status to the general health of all patients in their care, and the detrimental effect poor nutritional status can have if it is left untreated. 


\section{References}

Achenbach TM \& Edelbrock CS (1983) Manual for the Child Behavior Checklist and Revised Child Behavior Profile. Burlington, VT: Department of Psychiatry, University of Vermont.

Barrocas A, Belcher D, Champagne C \& Jastram C (1995) Nutrition assessment practical approaches. Clinics in Geriatric Medicine 11, 675-713.

Bishop CW, Bowen PE \& Ritchley PI (1981) Norms for nutritional assessment of American adults by upper arm anthropometry. American Joumal of Clinical Nutrition 34, 2530-2539.

Bryan F, Jones JM \& Russell L (1998) Reliability and validity of a nutrition screening tool to be used with clients with learning difficulties. Journal of Human Nutrition and Dietetics 11, 41-50.

Burr ML \& Phillips KM (1984) Anthropometric norms in the elderly. British Journal of Clinical Nutrition 51, 165-169.

Campbell MK \& Kelsey KS (1994) The PEACH survey: a nutrition screening tool for use in early intervention programs. Journal of the American Dietetic Association 94, 1156-1158.

Chernoff R (1994) Meeting the nutritional needs of the elderly in the institutional setting. Nutrition Reviews 52, 132-136.

Coulston AM, Craig L \& Voss AC (1996) Meals-on-wheels applicants are a population at risk for poor nutritional status. Joumal of the American Dietetic Association 96, 570-573.

Dwyer JT (1991) Screening Older Americans' Nutritional Health: Current Practices and Future Possibilities, pp. 1-136. Washington, DC: Nutrition Screening Initiative.

Edington J, Kon P \& Martyn CN (1996) Prevalence of malnutrition in patients in general practice. Clinical Nutrition 15, 60-63.

Edington J, Kon P \& Martyn CN (1997) Prevalence of malnutrition after major surgery. Journal of Human Nutrition and Dietetics 10, 111-116.

Elmore MF, Wagner DR, Knoll DM, Eizember L, Oswalt MA, Glowinski EA \& Rapp PA (1994) Developing an effective adult nutrition screening tool for a community hospital. Journal of the American Dietetic Association 94, 1113-1118.

Frisancho AR (1981) New norms of upper limb fat and muscle areas for assessment of nutritional status. American Journal of Clinical Nutrition 34, 2540-2545.

Gianino S \& St John RE (1993) Nutritional assessment of the patient in the intensive care unit. Critical Care Nursing Clinics of North America 5, 1-16.

Gilford A \& Khun Khun R (1996) Development of nutritional risk screening in the community. British Joumal of Community Health Nursing 1, 335-339.

Green SM \& McLaren SG (1998) Nutritional assessment and screening: instrument selection. British Journal of Community Nursing 3, 233-242.

Grindel CG \& Costello MC (1996) Nutrition screening: an essential assessment parameter. MEDSURG Nursing 5, 145-156.

Guigoz Y, Vellas B \& Garry PJ (1994) Mini Nutritional Assessment: a practical assessment tool for grading the nutritional state of elderly patients. Facts, Research and Intervention in Geriatrics 4, 15-59.

Guigoz Y, Vellas B \& Garry PJ (1996) Assessing the nutritional status of the elderly: The Mini Nutritional Assessment as part of the geriatric evaluation. Nutrition Reviews 54, S59-S65.

Ham RJ (1994) The signs and symptoms of poor nutritional status. Primary Care; Clinics in Office Practice 21, 33-54.

Hasse J, Strong S, Gorman MA \& Liepa G (1993) Subjective global assessment: alternative nutrition-assessment technique for livertransplant candidates. Nutrition 9, 339-343.
Hickson M \& Hill M (1997) Implementing a nutritional assessment tool in the community: a report describing the process, audit and problems encountered. Journal of Human Nutrition and Dietetics 10, 373-377.

Jensen GL, Kita K, Fish J, Heydt D \& Frey C (1997) Nutrition risk screening characteristics of rural older persons: relation to functional limitations and health care charges. American Journal of Clinical Nutrition 66, 819-828.

Klein S, Kinner J, Jeejeebhoy K, Alpers D, Hellerstein M, Murray M \& Twomey P (1997) Nutrition support in clinical practice: review of published data and recommendations for future research. Summary of a conference sponsored by the National Institutes of Health, American Society for Parenteral and Enteral Nutrition, and American Society for Clinical Nutrition. Journal of Parenteral and Enteral Nutrition 21, 133-156.

Lipschitz DA (1994) Screening for nutritional status in the elderly. Primary Care; Clinics in Office Practice 21, 55-67.

McWhirter JP \& Pennington CR (1994) Incidence and recognition of malnutrition in hospital. British Medical Joumal 308, 945948.

Mullan AP, Cleave N, Kennedy-Haynes L, Hackett AF \& Williams $G$ (1996) Validation of a simple nutrition risk score for use with the elderly in the community. Proceedings of British Dietetic Association Diamond Jubilee Conference, Poster 27 Abstr.

Nutrition Advisory Group for Elderly People (1992) Eating Through the 90s. Leeds: NAGE.

Posner BM, Jette AM, Smith KW \& Miller DR (1993) Nutrition and health risks in the elderly: the nutrition screening initiative. American Joumal of Public Health 83, 972-978.

Reilly H (1996) Nutritional assessment. British Joumal of Nursing $5,18,20-24$.

Reilly HM, Martineau JK, Moran A \& Kennedy H (1995) Nutritional screening - Evaluation and implementation of a simple Nutrition Risk Score. Clinical Nutrition 14, 269-273.

Sahyoun NR, Jacques PF, Dallal GE \& Russell RM (1997) Nutrition Screening Initiative Checklist may be a better awareness/educational tool than a screening one. Journal of the American Dietetic Association 97, 760-764.

Scanlan F, Dunne J \& Toyne K (1994) No more cause for neglect. Introducing a nutritional assessment tool and action plan. Professional Nurse 9, 382-385.

The Nutrition Screening Initiative (1994) Incorporating Nutrition Screening and Intervention into Medical Practice: A Monograph for Physicians, no. 1-73. Columbus, OH: Ross Products Division, Abbott Laboratories.

Ward J, Close J, Little J, Boorman J, Perkins A, Coles SJ \& Edington J ( 1998) Development of a screening tool for assessing risk of undernutrition in patients in the community. Journal of Human Nutrition and Dietetics 11, 323-330.

Westin T, Tradhgard C, Andersson K, Warnold I \& Edstrom S (1988) Nutritional assessment of hospitalized patients with head and neck cancer. Journal of Oto-Rhino-Laryngology and its Related Specialties 50, 193-198.

White JV (1994) Risk factors for poor nutritional status. Primary Care; Clinics in Office Practice 21, 19-31.

Wolinsky FD, Coe RM, Chavez MN, Prendergast JM \& Miller DK (1986) Further assessment of the reliability and validity of a nutritional risk index: analysis of a three-wave panel study of elderly adults. Health Services Research 20, 977-990.

Wolinsky FD, Coe RM, McIntosh WA, Kubena KS, Prendergast JM, Chavez MN, Miller DK, Romeis JC \& Landmann WA (1990) Progress in the development of a nutrition risk index. Journal of Nutrition 120, 1549-1553. 